\title{
China's path to the construction of low-carbon cities in the context of new-style urbanization
}

Shouyi Hao

Correspondence:

shouyihao88@sina.com

Urban and Regional Economy

Research Institute, Nankai University, No. 94 Weijin Road, Tianjin 300071,

People's Republic of China

\section{Springer}

\begin{abstract}
The core requirements of new urbanization are ecological cities and improvements to quality of life, and the construction of low-carbon cities is a necessary choice to achieve these requirements. This paper probes the definition of the low-carbon city, the principle spatial units of the low-carbon city system, and the mechanisms of the ecological and social systems of low-carbon cities, and briefly discusses the principles and systematic solution of low-carbon city construction in the context of new urbanization.
\end{abstract}

Keywords: New urbanization; Low-carbon areas; Low-carbon communities; Low-carbon city system

Currently, downward pressure on the global economy is increasing, growth is slowing, and China's investment and exports are lacking vigor. In the near term, domestic demand will be insufficient to reinvigorate the economy. A consensus has been reached that the investment and consumption structure has approached a 'turning point'. Not only has traditional urbanization not fixed the problems of domestic demand and consumption, but the problems and contradictions that have accumulated with the use of the old model are increasingly prominent. Therefore, adjustments to the investment structure and a transformation of urbanization are urgently needed.

The proposal of a new style of urbanization is aimed at using urbanization to boost domestic demand and using domestic demand to spur adjustments to the economic structure. Compared to conventional urbanization, new-style urbanization places more emphasis on the quality of city construction. New-style urbanization is driven by newstyle industrialization and based on the principle of planning that considers all factors. New-style urbanization promotes the modernization of cities, the clustering of cities, the greening of cities, and the urbanization of the countryside to fully elevate the quality and level of urbanization, achieve scientific development, and coordinate the development of large, medium, and small cities and towns that are scientifically developed, intensive and highly efficient, perfect in function, with good environments, and with social harmony, and which integrates urban and rural areas.

\section{The optimal choice of new urbanization: low-carbon city construction}

The core requirements of new-style urbanization in China are to continuously improve the quality of urban construction and improve the quality of life for

(c) 2014 Hao; licensee Springer. This is an Open Access article distributed under the terms of the Creative Commons Attribution License (http://creativecommons.org/licenses/by/2.0), which permits unrestricted use, distribution, and reproduction in any medium, provided the original work is properly cited. 
people in the process of urbanization. In the last few decades, China has experienced development and rapid urbanization that has driven the rapid development of the economy and society. But because of the coarseness of urbanization, China has accumulated a large number of problems as the economy has developed, and resource and environmental contradictions are more and more prominent. The consequences of this coarse development model obviously run counter to the urbanization goals of the government's original design. China's urbanization has moved further and further away from resource conservation and an amicable environment, and the discrepancy with urban greening and quality of life is even worse.

Besides income levels, public services, and social security, enhancing the quality of life also includes improving the ecological environment, which is also an important indicator of the improving quality of urbanization. There are two primary ways to improve the urban ecological environment: (1) low-carbon and ecological lifestyles and (2) low-carbon and ecological modes of production. Becoming low-carbon and ecological requires us to shift from traditional ways of living to a low-carbon life. This involves the practice of concepts including low-carbon consumption and low-carbon travel. A low-carbon and ecological lifestyle requires the low-carbon idea to penetrate the entire production process, from low-carbon planning, to low-carbon production, to popularizing clean energy and developing low-carbon industry. In fact, the process of making cities low-carbon is the process of constructing low-carbon cities. Thus, constructing low-carbon cities is a necessary choice in achieving new-style urbanization and increasing living standards.

Ecological cities and towns are an intrinsic requirement of new-style urbanization. Urbanization is a complex system comprised of subsystems including energy, construction, transportation, infrastructure, society and culture, and ecology (Ni 2013; Li 2012; Niu 2010). Thus, the process of making a city ecological involves making the industrial structure low-carbon and ecological, making the building system low-carbon, making the transportation system low-carbon, and making infrastructure and energy systems low-carbon and ecological. In fact, this is crucial for building low-carbon cities. The goal of making cities and towns ecological can be achieved through constructing lowcarbon cities. One can see that in China's new-style urbanization process, constructing low-carbon cities is a necessary choice in achieving ecological cities and towns and improving living standards. In this context, this article attempts to summarize the intent and formation of low-carbon cities based on a case study the China-Singapore Tianjin Eco-city.

\section{China-Singapore Tianjin Eco-city: the experience of low-carbon city construction in China}

China-Singapore Tianjin Eco-City is a national pilot program promoted by the Chinese and Singaporean governments in accordance with the principle of 'duplicable, functional, propagative'. It is the first national ecological city program in history, will help to establish a reference standard for the construction of ecological cities and low-carbon cities, and will become a model for the construction of low-carbon cities in China. 
The experience of the Sino-Singapore Ecological City will allow us to draw lessons for constructing low-carbon cities in the context of new urbanization.

\section{Overall planning and spatial layout of eco-cities}

The overall plan of the eco-city involves the construction of six systems: a healthy and natural ecological system, a sustainable energy system, a highly efficient industrial support system, friendly living communities, a harmonious and civilized cultural system, and a fair management system (Research Group of Sino-Singapore Eco-City 2010). In terms of the spatial layout, the plan uses a compact city layout to construct a comprehensive set of multiple functions including service industries, housing, and leisure as an integrated whole in an ecological valley and forges this into the main shaft of eco-city development. The land for the eco-city is divided into four parcels, named 'one axle, three cores and four sections,' which means combining the central section with the eco valley as the core of the whole city and building up another two central communities around the two light rail stations.

\section{Low-carbon parks, low-carbon communities, and green building construction}

China-Singapore Eco-city actively explores the model of the low-carbon park, particularly focusing on energy conservation and environmental protection, technical research and development, service outsourcing, cultural creativity, education and training, and exhibition and tourism to build a sustainable industrial system in order to provide powerful economic support to eco-city development.

The eco-city borrows from the 'zero-kilometer unit' concept from Singapore to build a low-carbon community. Within the eco-city, the residential green rate is no less than $40 \%$, and the proportion of policy-type housing is no less than $20 \%$. The concept integrates the city center to construct a comprehensive, multi-level, and fully functional public service system. Educational and medical services and other cultural and lifestyle facilities are distributed according to population size to ensure citizens have access to a full range of services within $500 \mathrm{~m}$.

The eco-city takes green buildings as the basic unit to build low-carbon parks and low-carbon communities and sets evaluation standards of green construction based on this basic unit. It refers to LEED (American), BREEAM (British), and other national evaluation standards such as Singapore's green building evaluation to formulate the 'Sino-Singapore Eco-city Green Building Evaluation', which is more stringent than the national standard.

\section{Construction of the support system of urban system operations}

In the process of building low-carbon parks, low-carbon communities, and green buildings, the China-Singapore Eco-city actively pays much attention to the construction of the city's support system. In the inner city, a public transportation system mainly composed of clean-energy buses is built around a light rail. By providing more public services for citizens within their walking range, the city reduces reliance on automobiles.

A four-level public service system will be constructed: 'Eco-city Center-Eco-city Secondary Center-Residential Community Center-and Grassroots Community Center' 
to ensure the construction of educational, health care, and cultural public facilities. A special focus will be placed on enhancing financial facilities, cultural facilities, sports facilities, healthcare services, and educational facilities.

With water conservation as the crucial consideration, a rainwater collection system and wastewater recycling system will be constructed, and concentrated wastewater treatment and wastewater resource use engineering will be implemented to raise the conventional water usage ratio by developing the techniques of reused water and seawater desalination.

The eco-city gives priority to developing reusable resources, prohibits the use of non-clean coal, low-quality fuel oil, and other high-polluting fuels to form an energy use model that is linked to conventional energy sources and where conventional and new energy sources supplement each other. It establishes a system for classification, collection, and reuse of solid wastes. It fully applies the construction energy-saving technologies and actively applies heat pumps to recover waste heat, thermoelectric cooling supply, ground solar collection, and other technologies to achieve comprehensive utilization of energy.

Establish a unified eco-city basic data platform to achieve a high degree of information sharing within the government and enhance the level of e-government construction. Construct an urban information management platform to achieve intelligent urban management through gridded, three-dimensional management, and carry out full-time, all-around, whole-process monitoring, processing, and feedback of urban components and incidents.

\section{Construction of an ecological system}

In ecological protection and ecological restoration, take appropriate ecological protection and restoration measures. With an ecological core area enclosed by the Jiyun River and Jiyun River Old Road, construct six ecological corridors to strengthen the link between the core ecological area and the peripheral ecosystem and form an open ecological spatial pattern to actively promote the integration of regional ecosystems.

In terms of environmental protection and health, establish a construction project environmental access system integrating construction project approval and environmental management. Establish an environmental monitoring network covering the entire area to strictly manage construction projects. Establish separated collection of garbage and an integrated treatment and cyclical use system, and actively explore advanced sanitary technologies like pneumatic collection of garbage.

\section{Construction of a social system}

In terms of culture and education, construct an eco-friendly forum to become a base for international exchange. Build a new platform of science and technology innovation to become a scientific and technical innovation base. Build supporting policy mechanisms to become an application demonstration bases. In lifestyle and consumption patterns, construct an eco-friendly science popularization, exhibition, and education base to popularize and spread environmental awareness. Through multiple channels, employ multiple forms to popularize and spread ecological and 
environmental knowledge to lead the social climate. Advocate the conservation of resources, civilized and healthy production methods, and consumption and lifestyles.

\section{Implications of the low-carbon city}

Judging by the statements above, one can see that the implications of the low-carbon city can be summarized as follows. The low-carbon city refers to closely connecting low-carbon parks and low-carbon communities through low-carbon transport, lowcarbon municipal policy infrastructure, low-carbon energy systems, intelligent urban management, low-carbon living, low-carbon consumption, and other intelligent urban operation systems, with the low-carbon park and the low-carbon community as the spatial carrier units, thereby forming a low-carbon urban system.

According to the experience of the China-Singapore Eco-city and the National Development and Reform Commission's 'Notice Regarding Pilot Work for the Development of Low-Carbon Provinces and Autonomous Regions and Low-carbon Cities', one can judge that only when a city meets the following conditions can it be called a lowcarbon city:

First is a low-carbon city development plan. A low-carbon city development plan includes work plans for adjusting the industrial structure, optimizing the energy structure, and others, and clearly proposed operational objectives, key tasks, and specific measures of reducing greenhouse gas emissions. Second is a reasonable city size. Too large of a city will result in wasted land, increased commute times and distances, increased costs of living, and increased emissions from transport. Too small of a city will restrict urban development, restrict the role of urban economies of scale, and reduce the level of residents' welfare. Therefore, the size of a city must be decided rationally based on development requirements. Third is a good layout. A compact urban form can greatly reduce the number of trips and distances residents must travel by car to perform various functions. A good public transport network can also reduce the proportion of automobile trips and thus reduce the quantity of carbon emissions. Fourth is an industrial system characterized by low-carbon emissions. This includes the establishment of a low-carbon industrial system, a highly efficient energy use system, and a low-carbon transportation system. Actively promote research and development of low-carbon technologies, demonstrations, and industrialization; and develop strategic emerging industries including conservation and environmental industries and clean energy industries. Fifth is a green construction system. Beginning with planning and construction, actively promote the application and adoption of energy conserving construction materials by guiding the construction process through rational planning and design, thus reducing energy consumption from construction works. Meanwhile, urban green areas should be increased within plans to achieve the effect of reducing the overall amount. Sixth is a greenhouse gas emissions monitoring and management system. Seventh is low-carbon lifestyles and consumption models. Encourage lowcarbon lifestyles and behaviors, actively popularize the use of low-carbon products, enhance the concept of the low-carbon lifestyle, and promote widespread participation and self-action of all residents. Eighth is intelligent urban management. Make full use of digital information management technologies and network communications 
technology and scientifically integrate various types of information resources in order to make low-carbon cities highly efficient, convenient, reliable, and dynamic digital cities.

\section{The composition of low-carbon cities}

The city is a complex organic system. It comprises the interconnection and interaction among production, lifestyle, ecology, culture, politics, and other subsystems. Lowcarbon cities are no different.

The basic spatial unit of the composition of low-carbon cities: low-carbon parks and low-carbon communities

Low-carbon parks are the spatial places of a low-carbon city bearing the weight of lowcarbon industrial production behavior and market behavior, and they are the basic spatial unit comprising the low-carbon city. They mainly refer to various types of productionoriented industrial parks. The construction of low-carbon parks is on one hand conducive to enhancing the overflow effect of concentrated technical, finance, and research and development institutions and their pulling effect on economic growth, conducive to the upgrading and optimization of the regional industrial structure and leading to the transformation of the economic model. On the other hand, the construction of low-carbon parks can effectively facilitate the formation of an industrial system characterized by low carbon emissions and thus reduce the level of urban energy construction and the concentration of greenhouse emissions. Thus, constructing low-carbon cities requires more efforts to promote the construction of low-carbon parks.

The low-carbon community is the spatial carrier for human life and residence. In the process of low-carbon urban construction, low-carbon work directly related to the urban system is conducted within the scope of the community space, especially low-carbon construction materials, low-carbon energy system, low-carbon resource use, low-carbon social environment, low-carbon lifestyles and consumption patterns, etc. Thus, one of the key tasks in constructing low-carbon cities is constructing low-carbon communities.

Low-carbon buildings are the basic factors comprising low-carbon parks and lowcarbon communities. They appear in the low-carbon urban system in the form of residences, factories, and office buildings. Buildings on the one hand provide the needed space for corporate production, human habitation, business offices, and consumption. On the other hand, they are large emitters of carbon. Thus, accelerating the shift to low-carbon buildings is both an expression of the shift to low-carbon cities in the field of buildings and a foundation for building low-carbon parks and low-carbon communities, increasing efficiency, reducing emissions, and enhancing the quality of urban life and the environment.

\section{The support system for low-carbon cities}

Besides possessing the two basic spatial units of low-carbon parks and low-carbon communities, a low-carbon city must also have a system that can effectively link different lowcarbon parks and low-carbon communities, and support the operation of urban functions. In this article, the low-carbon urban operation system refers to a low-carbon transportation network, low-carbon public infrastructure (roads, communications, etc.), low-carbon 
municipal facilities, low-carbon energy, and low-carbon consumption. It is based on such a system that the various subsystems composing the low-carbon city produce their widespread economic links, societal links, ecological links, and political and cultural links. Thus, the construction of a low-carbon city should include the shift to a low-carbon urban system.

\section{The ecosystem of the low-carbon city}

In the process of making cities low carbon, ecosystem construction consists of two parts. First is the ecosystem of the city itself. Second is the natural ecosystem of nearby areas. In the urban cycle, low-carbon parks, low-carbon communities, and other functions of the city are main emitters of greenhouse gases, mainly carbon dioxide, while the natural ecosystem of the surrounding areas is an absorber of carbon dioxide. Using the laws of ecology, actively promote the construction of an ecosystem within the low-carbon city to build an urban ecosystem that is stable in ecological functions and close in form to a natural ecosystem. While constantly integrating the city into the natural environment, it is essential to increase carbon sinks and a good-living effect where the city and its residents are ecological.

\section{The social system of the low-carbon city}

In addition to efforts on constructing the hardware of low-carbon cities (including industry, transportation, buildings, and municipal facilities), efforts must be made to strengthen the construction of the software of low-carbon cities, particularly the social system composed of the cost of living, culture, and education.

Advocate for low-carbon living and develop a low-carbon culture. Change the current consumer attitudes and lifestyles and build a mainstream viewpoint that suits 'lowcarbon'. Internalize the low-carbon concept in social production and people's lives, and ultimately change the production and living behavior of the economy and society.

The construction of a low-carbon city does not only consist of developing the circular economy, conserving energy, and reducing emissions. It also involves all types of construction in production, living, ecology, human affairs, society, and more. Figure 1 shows the components of the urban system and their interaction.

\section{Basic thinking on building low-carbon cities}

Based on the aforementioned analysis, through the meaning, characteristics, and urban system concept of the low-carbon city, one can see that the following points should be noted in constructing low-carbon cities.

The construction of a low-carbon city requires an overall scientific plan and rational spatial layout

The low-carbon city is a complex organic system. Thus, the construction of a lowcarbon city requires the implementation of an overall plan. This plan should lay stress on the feasibility of each individual plan as well as the coordination and interaction among the various individual plans so that the individual plans work with the overall urban development plan to mutually promote the rational layout of urban space. 


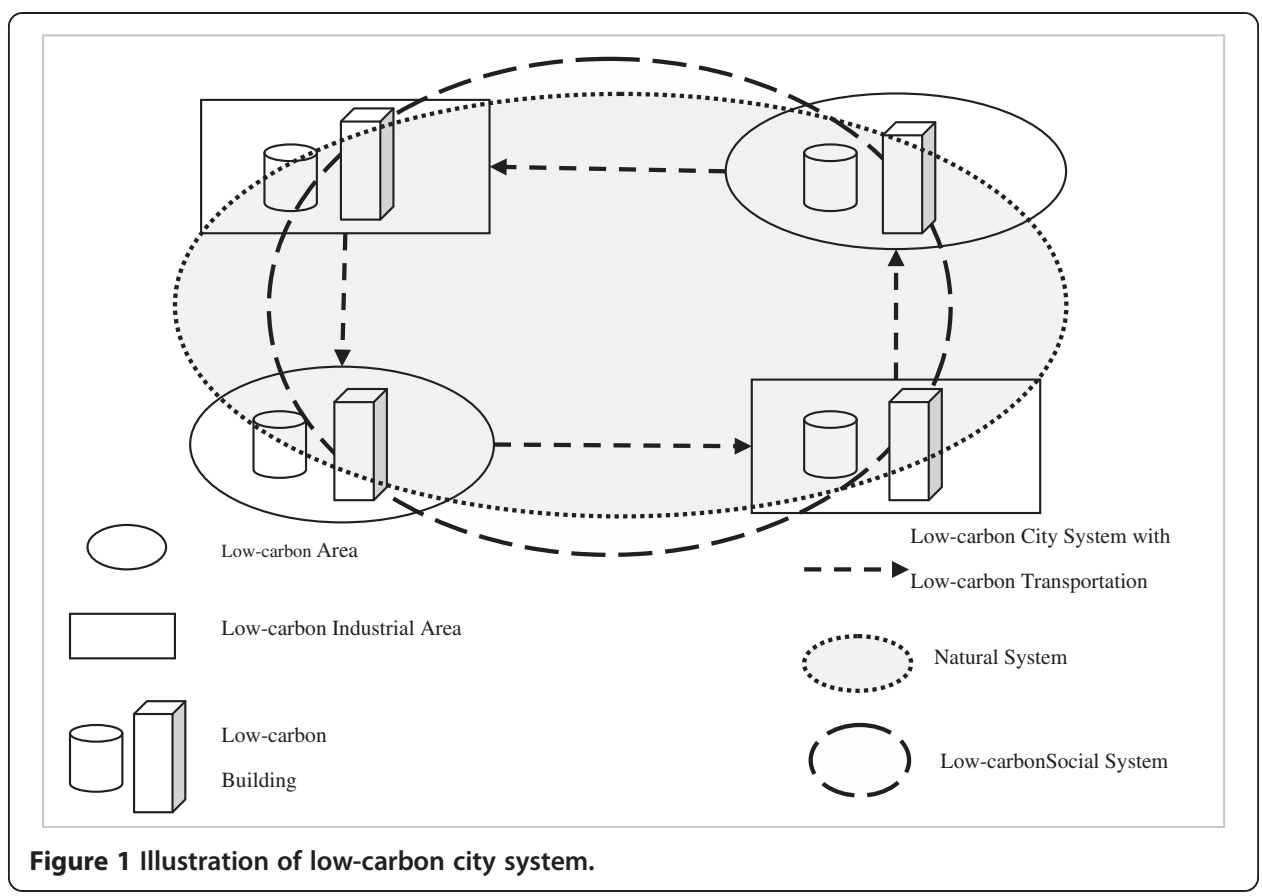

\section{Stress the construction of low-carbon parks and communities}

Constructing low-carbon parks is the key to promoting low-carbon technology and industrializing low-carbon products. The establishment of low-carbon parks can provide a positive development environment for low-carbon industry and a platform for research, development, and incubation of technology. Building low-carbon parks requires building a good investment environment, actively attracting low-carbon companies and technicians that understand key technologies and providing preferential fiscal and tax policies to encourage the entrance of private capital. Meanwhile, actively follow up with the construction of related policies, laws, and service systems. Actively push forward the construction of low-carbon communities and shift to low-carbon lifestyles and consumption models by constructing low-carbon communities. Specific measures include the following: (1) shifting to low-carbon planning and design, (2) shifting to low-carbon building materials, (3) shifting to a low-carbon community environment, (4) shifting to a low-carbon energy system, (5) shifting to low-carbon resource use, and (6) shifting to low-carbon lifestyles.

\section{Stress the construction of low-carbon urban ecosystem}

The urban ecosystem is led by the main entities of the city, including the entities transforming production methods and the entities transforming lifestyles: companies and residents. Whether in terms of ecological protection and restoration, in terms of construction of the nearby natural scenery system, or in terms of environmental protection and environmental sanitation, companies and residents participate jointly. Thus, the construction of the low-carbon urban ecosystem, in addition to actively pushing forward the construction of the aforementioned three aspects, also requires actively researching how to increase the capacity of carbon sinks and reduce the intensity of carbon emissions. 


\section{Stress the construction of the low-carbon urban social system}

Through a variety of forms, increase the coverage and intensity of propaganda and education. Advocate the concept of low-carbon consumption and promote low-carbon lifestyles. Allow government entities to play a role of setting an example and guiding construction of the social system (Lin et al. 2011).

\section{The role of the government}

At present, the construction of China's market mechanisms, policy, and legal system is not yet complete. In this case, the construction of low-carbon cities and the development of low-carbon industry require the participation, leadership, and management of the government. The government must scientifically plan rational layouts and play a guiding role in planning, improve policies and laws, enhance enforcement capabilities, and guarantee that the law is followed, advocate low-carbon consumption, foster lowcarbon lifestyles, spread the low-carbon message, and set an example. The government must also construct a comprehensive assessment mechanism to expand low-carbon performance assessments and incentives. Furthermore, the government has to clarify responsibilities and goals and strengthen the accountability system. In addition, the government must also play a policy-guidance role to indirectly guide and control the development of low-carbon industry and the construction of low-carbon cities on a macro level and thereby the development goal of encouraging and supporting the lowcarbon economy and ultimately achieve the requirement of new-style urbanization.

Competing interest

The author declares that he has no competing interests.

Authors' information

SH was born in Hejian, Hebei Province in 1952. He is a professor, secretary-general, and doctoral supervisor at the Urban and Regional Economy Research Center at Nankai University. He is also the director of the Binhai Research Institute of Tianjin, the executive deputy director of the National People's Congress at Binhai New Area, Tianjin, the chairman of the Regional Science Association of China, and the vice-chairman of the Regional Economic Association of China. His research interests include urban and regional economy, and land and real estate economy.

Received: 5 February 2013 Accepted: 8 November 2013

Published: 3 January 2014

References

Ni P (2013) The module, path and proceeding policies of new-approach urbanization (新型城镇化的基本模式、 具体路径与推进对策). Jianghai Academic Journal (江海学刊) 1:87-94

Li Y (2012) Road of China and new urbanization (中国道路与新城镇化) [M]. The Commercial Press (商务印书馆), Beijing

Niu W (2010) Recognition of strategic of Chinese new-approach urbanization (中国新型城市化战略认识) [J]. Impact of Science on Society (科学对社会的影响) 1:14-20

Research Group of Sino-Singapore Eco-City (2010) Guide of eco-city: index system and implementation of Sino-Singapore eco-city (导航生态城市: 中新天津生态城指标体系实施模式) [M]. China Architecture \& Building Press (中国建筑工业出版社), Beijing

Lin X, Wang B, Feng J (2011) Urban governance of Sino-Singapore Tianjin eco-city (中新生态城的城市治理研究). Journal of Tianjin University (Social Sciences) (天津大学学报:社会科学版) 3:284-287 